Int. J. Dev. Biol. 49: 547-555 (2005)

doi: $10.1387 /$ ijdb.041921ht

\title{
Leaf shape: genetic controls and environmental factors
}

\author{
HIROKAZU TSUKAYA*
}

\begin{abstract}
National Institute for Basic Biology/Okazaki Institute for Integrated Bioscience, Myodaiji-cho, Okazaki, Japan, Graduate University for
\end{abstract} Advanced Studies, Hayama, Kanagawa, Japan and Graduate School of Science, Kyoto University, Kyoto, Japan

\begin{abstract}
In recent years, many genes have been identified that are involved in the developmental processes of leaf morphogenesis. Here, I review the mechanisms of leaf shape control in a model plant, Arabidopsis thaliana, focusing on genes that fulfill special roles in leaf development. The lateral, two-dimensional expansion of leaf blades is highly dependent on the determination of the dorsoventrality of the primordia, a defining characteristic of leaves. Having a determinate fate is also a characteristic feature of leaves and is controlled by many factors. Lateral expansion is not only controlled by general regulators of cell cycling, but also by the multi-level regulation of meristematic activities, e.g., specific control of cell proliferation in the leaf-length direction, in leaf margins and in parenchymatous cells. In collaboration with the polarized control of leaf cell elongation, these redundant and specialized regulating systems for cell cycling in leaf lamina may realize the elegantly smooth, flat structure of leaves. The unified, flat shape of leaves is also dependent on the fine integration of cell proliferation and cell enlargement. Interestingly, while a decrease in the number of cells in leaf primordia can trigger a cell volume increase, an increase in the number of cells does not trigger a cell volume decrease. This phenomenon is termed "compensation" and suggests the existence of some systems for integration between cell cycling and cell enlargement in leaf primordia via cell-cell communication. The environmental adjustment of leaf expansion to light conditions and gravity is also summarized.
\end{abstract}

KEY WORDS: Arabidopsis thaliana, compensation, environmental factor, gene, leaf organogenesis

\section{Biological significance of leaf shape}

Leaves are photosynthetic organs; thus, the shapes and sizes of leaves are very important factors influencing the success of plants. To absorb sufficient light energy, leaves must be as wide as possible. At the same time, to facilitate gas exchange (CO2, $\mathrm{O} 2$ and $\mathrm{H} 2 \mathrm{O}$ ), leaves must be as flat and thin as possible. However, if leaves are too wide and too thin, they will quickly become desiccated. Thus, leaf area and thickness are restricted by the availability of water in main.

In addition to the above-mentioned basic environmental factors, other factors can affect the optimum shape and size of leaves. For example, plants that are adapted to riparian habitats which are frequently flooded typically develop narrow, thick leaves. Plants with such morphological adaptations are categorized as rheophytes (van Steenis 1981). Typical rheophytes show two types of adaptations to two opposite types of environmental stress. Leaves of rheophytes are narrower than closely related species and are thus able to resist the strong flow of water. On the other hand, leaves of rheophytes are thicker than those of their ancestral species in order to tolerate desiccation during exposure to high levels of sunshine in fair weather.

Although shape of leaves is genetically fixed in a particular type in most rheophytes, leaf shape in a species is not necessarily fixed as one type by evolutionary traits. Many species have acquired plasticity of leaf shape allowing responses to environmental conditions. When plants are exposed to weak light, most show a shade-avoidance syndrome, e.g., an elongation of the petiole and a decrease (sometimes increase) of the leaf blade area. The shade-avoidance syndrome is a typical example of leaf shape plasticity. In a model plant, Arabidopsis thaliana (L.) Heynh. (Arabidopsis, hereafter), leaf-blade expansion is inhibited and, at the same time, petiole elongation is enhanced when the shadeavoidance syndrome is triggered (Nagatani et al., 1991; Reed et al., 1993; Tsukaya et al., 2002; Kozuka et ak., 2005). This change in leaf shape provides for a better leaf position. As the efficiency of photosynthesis is low unless leaves can absorb sufficient light, it is

Abbreviations used in this paper: LCD, lower cell density gene.

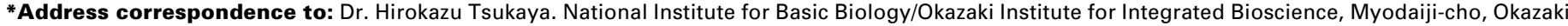
444-8585, Japan. Fax: +81-564-55-7512. e-mail: tsukaya@nibb.ac.jp
} 
reasonable that leaves exhibiting shade-avoidance syndromes remain smaller by restricting the proliferation of leaf cells (Tsukaya et al., 2002).

As briefly summarized above, the control of leaf shape is the most important mechanism for plant success and has been refined through the course of evolution. Here, I review the genetic background behind leaf shape control in Arabidopsis.

\section{Basic mechanism of leaf organogenesis: dorsoventrality}

A leaf is classically defined as a determinate organ that exhibits dorsoventrality. In most species, the adaxial side of the leaf blade (which faces the shoot apical meristem, SAM) differentiates into palisade cells, while the opposite, abaxial, side differentiates into spongy cells in the parenchymatous layers. A lateral meristem occurs at the junction between the stem and adaxial sides of the base of the leaf. Dorsoventrality plays an important role in the establishment of leaf blades. First, a short-lived marginal meristem is activated along the rim of the adaxial/abaxial boundary, changing rod-shaped leaf primordia into spatula-like shapes (Donnelly et al., 1999). After initiation of the leaf lamina by the short-lived marginal meristem, cell proliferation for leaf lamina expansion is replaced by the activity of the plate meristem established inside the leaf primordia (Fig. 1). The establishment of dorsoventrality appears to be coupled with the two-dimensional, flat structure of leaf blades (Waites and Hudson 1995).

Dorsoventrality in leaves is determined in two opposite ways: adaxialization and abaxialization (Fig. 2). Several genes are involved in the processes of adaxialization and abaxialization. The class III HD-ZIP genes REVOLUTA (REV), PHABULOSA (PHB ) and PHAVOLUTA (PHV) are responsible for adaxialization (McConnell etal., 2001; Otsuga etal., 2001), whereas the KANADI and YABBY gene families are responsible for abaxialization (Siegfried et al., 1999; Sawa et al., 1999; Eshed et al., 2001; Kerstetter et al., 2001). The precise expression pattern of class III HD-ZIP genes in the adaxialization pathway is controlled by

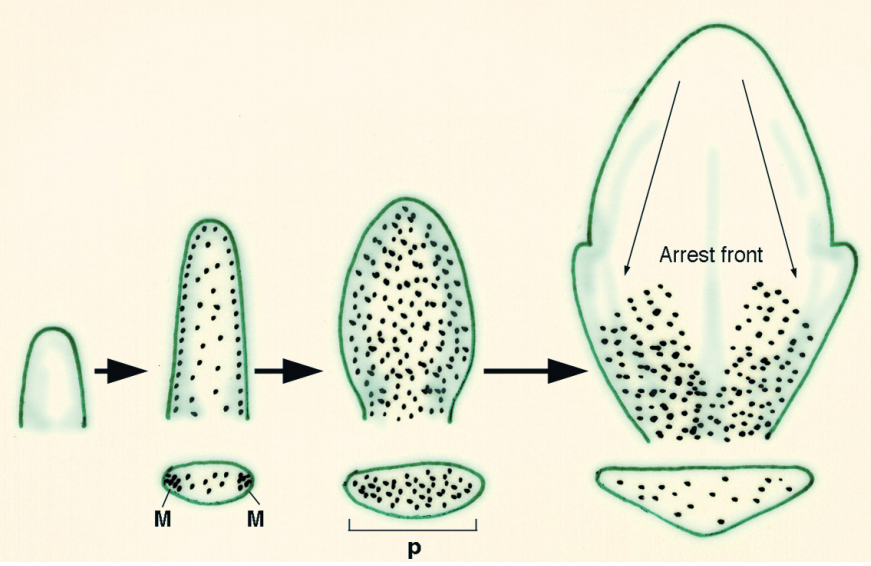

Fig. 1. Schematic of the establishment of leaf blades. Spatial pattern of activity of cell proliferation is shown in dots. The short-lived marginal meristem (M) converts rod-shaped initial leaf primordia into flat primordia the plant meristem $(P)$ is then activated to produce wider leaf blades. Several genes are thought to affect arrest front of the meristematic activity (shown by arrows) in the primordia.
microRNAs (miRNA165 and miRNA166 in Arabidopsis: Rhoades et al., 2002; Reinhart et al., 2002; Emery et al., 2003; Tang et al., 2003; Fig. 2). Thus, a component of the RNA silencing machinery, ARGONAUTE1 (AGO1), is also required for dorsoventrality of leaves via the proper regulation of miRNA165/166, which targets the cleavage of class III HD-Zip mRNAs (Bowman 2004; Kidner and Martienssen 2004). The microRNA-dependent regulation system is conserved among all land plants, i.e., angiosperms, gymnosperms, ferns, lycopods and mosses (Floyd and Bowman, 2004). This is a rather surprising finding, as «leaves» are thought to have evolved independently in these phylogenies.

\section{Determinate feature of leaf primordia}

Determinate growth is also an important characteristic of leaves. In contrast to the indeterminate SAM from which leaf primordia arise, leaves are determinate organs, although a few exceptions exist (Rutishauser and Sattler, 1985). Members of the genera Monophyllaea and Streptocarpus (Gesneriaceae; Jong and Burtt, 1975; Tsukaya, 1997; Imaichi et al., 2000) and of the genera Chisocheton and Guarea (Sattler and Rutishauser, 1992; Lacroix and Sattler, 1994; Fukuda et al., 2003) are typical examples of plants that develop indeterminate leaves. However, in most species, leaves are determinate. The most basic leaf form is «simple» and is represented by leaves of most model plants, including Arabidopsis, Antirrhinum majus L. and Zea mays L. Simple leaves show more or less serration in the margin but are not separated into several units. On the other hand, tomato, rose and white clover are typical species with compound leaves, which result from repeated organogenesis of leaflets on a primordium. Compound leaves are leaves that grow as a complex of several units of leaf-like organs, called leaflets. The difference between compound leaves and simple leaves is related to the expression pattern of a plant-specific homeobox gene family, class I KNOX genes. Class I KNOX genes are transcribed in the SAM but are specifically down-regulated in the primordia of simple leaves. On the other hand, the primordia of most compound leaves maintain mRNA expression of class I KNOX genes (Barathan et al., 2002). The overexpression of class I KNOX in tomato enhances the repeated organogenesis of leaflets, resulting in "super-compound leaves» (Hareven et al., 1996). Even Arabidopsis, which develops simple leaves, produces deeply serrated or segmented leaves when class I KNOX genes are ectopically expressed in the leaf primordia (Lincoln et al., 1994; Chuck et al., 1996). Exceptions to the relationship between the expression of class I KNOX genes in primordia and the organogenesis of compound leaves are known only in a particular group of the Leguminosae (Fabaceae). Class I KNOX genes are not transcribed in the primordia of compound leaves in the pea, Pisum sativum (Hofer et al., 2001). Instead, the development of compound leaves in the pea is dependent on the expression of the UNIFOLIATA gene, a homolog of $\angle E A F Y$ in Arabidopsis (Hofer et al., 1997).

At present, many studies are focused on the mechanisms of precise regulation of the expression pattern of the class I KNOX. A number of genes are involved in the down-regulation of class I KNOX genes in the primordia of simple leaves: $A S Y M M E T R I C$ LEAVES1 (AS1), AS2, BLADE-ON-PETIOLE1 (BOP1), SERRATA (SE) and PICKEL (PKL ; Byrne et al., 2000; Ori et al., 2000; Semiarti et al., 2001; Prigge and Wagner, 2001; Iwakawa et al., 


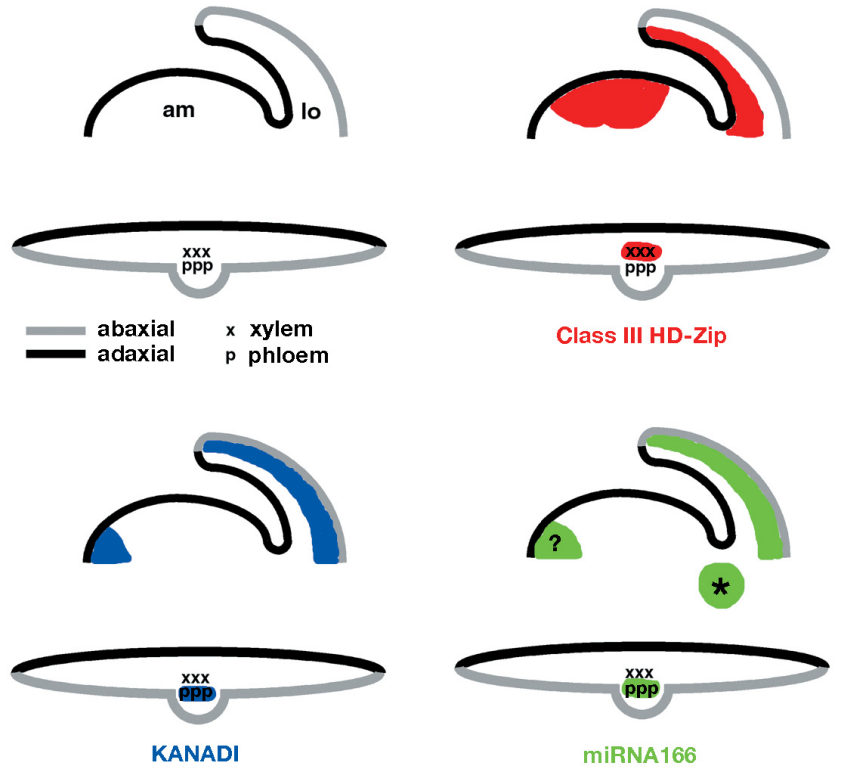

Fig. 2. Simplified model of the expression patterns of RNAs for the establishment of dorsoventrality in the shoot apex. The differentiation of the leaf primordia from the flanks of a shoot apical meristem (am) and the establishment of the dorsoventrality of the leaves (reproduced from Bowman, 2004).

2002; Ha et al., 2004). The morphological phenotypes of the mutants as1 and as2 have some similarity with a transgenic Arabidopsis which ectopically expressed class I KNOX genes, resulting in the segmentation of leaf primordia (Tsukaya and Uchimiya, 1997; Ori et al., 2000; Semiarti et al., 2001). However, although all three mutants, as 1, as2 and bop, show similar defects in the appropriate suppression of the accumulation of class I KNOX mRNA in the leaf primordia of Arabidopsis, the morphological phenotypes do not completely match each other (Fig. 3). Moreover, phenotypes of these mutants differ from those exhibited by an ectopic expressor of the class I KNOXgenes, such as KNAT1 (Fig. $3)$, suggesting that these genes target genes in addition to class I KNOX genes and that each of these three genes plays a unique role in leaf organogenesis.

In particular, the phenotype of bop1-1 is quite different from those of the other mutants (Fig. 3). Moreover, the bop1-1 mutation enhances the phenotypes of the as 1 and as 2 mutants ( $\mathrm{Ha}$ et al., 2003), while the as 1/as2 double mutant does not show a novel phenotype. This suggests that the BOP1 gene has a unique function other than the suppression of class I KNOX gene expression in leaf primordia. In fact, the bop 1-1 mutation enhances the phenotypes of an ectopic expressor of class I KNOX genes, resulting in repeated organogenesis on a single leaf primordium (Fig. 3). These data suggest that the ectopic expression of class I KNOX genes is responsible for the segmentation of leaf primordia, but is not sufficient for repeated organogenesis. Targets of the BOP1 gene may be involved in the suppression of repeated organogenesis in a leaf primordium. Coincident with the above idea, not all compound-leaf primordia that express class I KNOX genes develop compound leaves (Bharathan et al., 2002) and the enhanced effect of the ectopic expression of class I KNOX genes in repeated organogenesis in tomato compound leaves is weakened by some morphological mutations (Hareven et al., 1996). Although the roles of class I KNOX genes are often thought to lie simply in the maintenance of meristematic activity or repeated organogenesis, more prudent discussion is needed for the interpretation of the function of the KNOX regulators in leaf morphogenesis.

\section{Spatial control of meristematic activities in leaf primordia}

As mentioned above, after the determination of the adaxial/ abaxial boundary in the leaf primordium, the marginal and plate meristems act to develop the flat blade (Fig. 1). The marginal meristem is short-lived and plays a limited role in leaf organogenesis (Donnelley et al., 1999). Cell proliferation in the leaf margins seems to be dependent on a particular type of meristem that differs from the plate or marginal mersitems. Nath et al. (2003) reported that the cincinnata (cin) mutant of Antirrhinum majus develops crinkly leaves. CIN encodes a member of the TCP gene family. An analysis of cell cycling in wild-type and cin leaf primordia suggested that arrested cell cycling in the leaf margins occurs later in the cin mutant than in the wild type. As a result, cell proliferation is more prolonged in the leaf margins than in the central regions of the cin mutant leaf blades, causing the leaves to become crinkly (Nath et al., 2003). In Arabidopsis, the overexpression of a microRNA, miR-JAW, which can target the mRNAs of CIN homologs, also causes crinkly leaves (Palatnik et al., 2003), supporting the generality of the idea that $C / N$ homologs are involved in the control of cell cycling in the leaf blades. Similar spatial differentiation between the central area and the margin is also known for trichome differentiation: the control in the leaf margins differs from that in other areas of the leaf lamina (e.g., Kirik et al., 2004).

The local control of cell proliferation in the leaf primordia is also apparent when comparing leaf shapes among mutants and

Fig. 3. Morphology of the leaves of Arabidopsis thaliana mutants defective in the proper downregulation of class I KNOX gene expression in the leaf primordia. From left, wild type, as1, as2 and bop1 mutants, a transgenic line that expresses KNAT1 gene under control of cauliflower mosaic virus $35 S$ promoter and bop1 mutant that expresses a class I KNOX gene from fern under control of the same promoter. Note the prolonged morphogenesis of the leaf blade-like structure in these mutants as compared with wild-type leaves. Also note the morphological differences among the mutants. Unit of scale, $1 \mathrm{~mm}$.

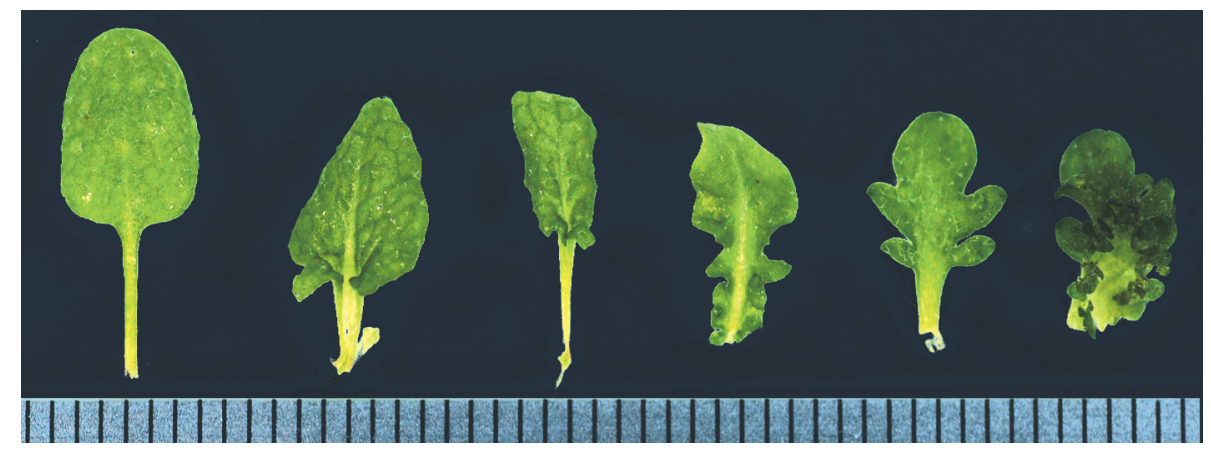


transgenics exhibiting defects in the cell proliferation machinery. As has been reported for an overexpressor of KIP-RELATED PROTEIN2 (KRP2), defects in overall cell proliferation sometimes cause deep serration, which may result from a lack of sufficient cell numbers in the margins (De Veylder et al., 2001). On the other hand, the loss-of-function mutants of ribosomal protein, pointed first leaf $1 n$ ( $p f / 1)$ and $p f l 2$, have shallow serrations of the leaves and the mutant leaves are much smaller than wild-type leaves (van Lijsebettens et al., 1994; Ito et al., 2000). Thus, cell cycling and housekeeping machinery may also be differentiated spatially between the leaf margin and the central area of the leaf blade. From this viewpoint, the fact that the ectopic expression of class I KNOX genes causes deep serration is an interesting clue to understanding the mechanisms of the spatial regulation of meristematic activity in leaf primordia.

\section{Two-dimensional control of leaf shape by polar cell proliferation}

A leaf or leaflet blade has a two-dimensional, flat shape. Variations in the leaf index (i.e., the ratio of the leaf length to width) are frequently observed in wild species and these variations are dependent on variations in the number or distribution of leaf cells in the leaf lamina (reviewed by Tsukaya, 2002a). This suggests that cell proliferation is controlled along two main axes, longitudinal (proximo-distal or leaf-length) and lateral (left-right or leaf-width), as evidenced in the expansion of leaf blades discussed below (Tsuge et al., 1996; Fig. 4).

In Arabidopsis, the leaf length can be specifically controlled via the regulation of the number of leaf cells by the ROTUNDIFOLIA4 (ROT4) peptide (Narita et al., 2004; Fig. 4). We identified the ROT4 gene by analyzing an enhancer-trap line of Arabidopsis, rot4-1D, which has stunted leaves. Rot4-1D leaves have fewer leaf cells predominantly in the leaf-length direction and show no defects in the size of leaf cells (Narita et al., 2004). The genome of Arabidopsis has 22 homologs of ROT4 (RTFL = ROT FOUR-LIKE), which

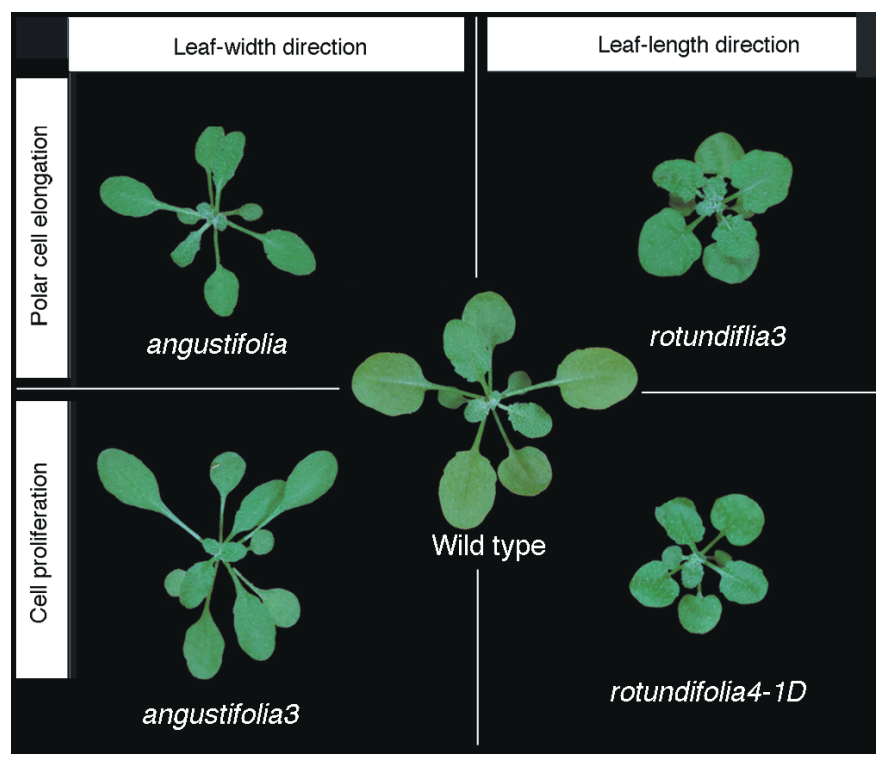

Fig. 4. Mutants of the regulators of the two-dimensional control of polar cell expansion and cell proliferation in leaves. See text for details. include 21 members of the DEVIL family (Wen et al., 2004). As the RTFL genes are short ( $R O T 4$ encodes 53 amino acids and has no intron), most members, including ROT4 itself, are non-annotated. All members of the RTFL family contain a conserved 29-amino acid domain, called the RTF domain and the overexpression of the ROT4 RTF domain alone is sufficient to decrease leaf length. The overexpression of DEVIL1 (= RTFL 18) causes a phenotype very similar to ROT4 overexpression (Wen et al., 2004). Thus, the fundamental function of the RTFL members, including the DEVIL family, appears to be the same. The loss-of-function of a member of $R T F L$ shows no visible phenotype, which might be explained by the high redundancy of the RTFL gene family (Narita et al., 2004). The RTFL gene family has thus far been found only in angiosperm genomes (Narita et al., 2004) and the rice genome has 23 members of RTFL (T. Yamaguchi, unpublished data). Considering that the organogenesis of leaves in the Gramineae, including rice, is highly dependent on cell proliferation in the longitudinal direction, an analysis of the role of RTFL genes in the Gramineae is warranted.

On the other hand, the specific control of cell proliferation in the leaf-width direction has not been reported to date. We found that the loss-of-function of the ANGUSTIFOLIA3 (AN3) gene, which encodes a transcriptional coactivator, results in a narrow leaf shape (Fig. 4) with a decreased number of leaf cells; however, the defect in the number of cells is not specific to the leaf-width direction (Horiguchi et al., 2005). In the case of the an3 mutant, the activity of the plate meristem, which supplies the cells in the lamina with randomized directions of cell division, is decreased. The period of cell proliferation is not shortened in the an3 leaf primordia, although the frequency of cell cycling is decreased, resulting in an3 leaves with fewer cells (Horiguchi et al., 2005). Interestingly, in the an3 mutant, the final volume of the leaf cells is much larger than that in the wild type, which compensates to some extent for the effect of fewer leaf cells per leaf area. This «compensation» system will be discussed in a later section.

In addition to the two-dimensional control of cell cycling in leaf primordia, differential control of cell proliferation with a proximaldistal polarity is also important in determining leaf shape. Wild-type leaf primordia differentiate into leaf blades at the distal part of the primordia, while the proximal part of the primordia develops into the leaf petiole. The overexpression of $\angle E A F Y$ PETIOLE (LEP), a transcription factor with a DNA-binding domain for members of the AP2/EREBP family, affects the proximo-distal differentiation of leaf blades. Leaf blades of the $\angle E P$ overexpressor are decurrent along the petiole, suggesting that the development of the leaf blade continues along the leaf petiole by the ectopic expression of $\angle E P$ (van der Graaff et al., 2000). Unfortunately, because the loss-offunction of the $\angle E P$ gene shows no visible phenotype, the native function of $\angle E P$ is still unknown.

\section{Other characteristic regulators of leaf cell number}

Most mutations of meristematic activity in the shoot apical meristem, including mutations of cell cycle regulators and phytohormone-related genes, also show defects in leaf shape or size. Moreover, the number of leaf cells is known to be regulated by many housekeeping genes, such as the genes for regulators of transcription. In the following paragraphs, several characteristic factors for cell cycling that have specific effects on leaf organogen- 
esis are described. For more general factors, see earlier reviews (Tsukaya, 2002a, b; 2003).

Some genes have a limited effect on the supply of leaf cells. For example, a loss-of-function mutant of the JAGGED (JAG) gene, which encodes a protein with a single $\mathrm{C} 2 \mathrm{H} 2$ zinc-finger domain, exhibits a defect in the development of the distal parts of leaves and floral organs. In contrast, the overexpression of JAG stimulates the growth of leaf blades and even actualizes cryptic leaves on inflorescences (Dinnenly et al., 2004; Ohno et al., 2004). However, the ectopic proliferation of other cell types, such as stem cells, does not occur. Thus, the expression of $J A G$ appears to stimulate the supply of cells only after the leaf blade has been identified by other genetic controls. Dinnenly etal. (2004) speculated that JAG1 plays an important role in the development of the distal part of leaf blades. However, JAG1 seems not to be restricted to the formation of the distal part of leaf blades, as decurrent leaf blade formation extending to the inflorescence stem and actualized cyrptic leaves are seen in the overexpressor (Ohno et al., 2004).

On the other hand, the LOWERCELL DENS/TY1 (LCD1) gene, which has no similarity to known protein genes, plays a specific role in the supply of parenchymatous cells (Barth etal., 2003). The /cd11 mutant has fewer parenchymatous cells in the leaf lamina, although the leaf size is not very small owing to the greatly increased air space in the leaves. This mutant phenotype suggests that there are cell-cycle regulatory systems specific to parenchymatous cells in the leaf lamina.

Taken together, the regulating factors of cell cycling in leaf blades can be categorized into several types, from those affecting the activity of cell cycling in all cell types, to those that affect in a particular cell types or along a particular polarity (e.g., ROT4), those that extend or stimulate cell proliferation only when leaf organogenesis is permitted (e.g., JAG) and those that affect only a certain part of the leaf (e.g., JAW for cell proliferation in the marginal area). Multi-leveled control of cell proliferation in leaf primordia may be essential for the fine control of the organogenesis of leaves with a flat structure.

\section{Two-dimensional control of leaf shape by polar cell expansion}

Leaf expansion involves two developmental events: cell proliferation and cell expansion. The two-dimensional expansion of leaf blades depends on two independent, polarized regulators of cell expansion: ANGUSTIFOLIA $(A N)$, which regulates the polar expansion of leaf cells in the leaf-width (lateral) direction and ROTUNDIFOLIA3 (ROT3), which regulates the polarized growth of leaf cells in the leaf-length (longitudinal) direction (Tsuge et al., 1996; Fig. 4). The two-dimensional expansion of leaf blades is also controlled by the regulation of cell proliferation, as discussed above. Thus, both cell expansion and cell proliferation appear to be under the control of two polarities, the longitudinal and lateral axes (Fig. 4).

$A N$ encodes a homolog of the animal Carboxyl-terminal-binding protein $(C t B P)$ and may be related to the control of the cortical microtubule arrangement in leaf cells (Kim et al., 2002). CtBPs function as co-repressors and regulate the developmental processes in Drosophila, Xenopus and other animals, while the closely related homolog of CtBPs, brefeldin A-ADP ribosylated substrate protein (BARS), is involved in the formation and mainte- nance of the Golgi apparatus (Cinnadurai, 2002; Nardini et al., 2003). Curiously, the amino acid sequence of CtBPs which function in the nucleus closely resembles that of BARS which functions in the cytoplasm. The molecular function of AN, which represents a member of the third subfamily of the CtBP/BARS family, remains to be determined. Let us call this gene family CBA (CtBP-BARS$A N$, Tsukaya, 2005). Interestingly, $\mathrm{AN}$ is associated with a kinesinlike protein, ZWICHEL (Folkers et al., 2002) and is homodimerized (Kim et al., 2002) in yeast cells. $A N$ homologs from plants are very similar to each other and have specific motifs that are not found in animal CtBPs (Kim et al., 2002; Cho et al., 2005). Further analyses of the molecular functions of these motifs in the AN subfamily, compared with the CtBP/BARS family, are needed.

On the other hand, ROT3 encodes a plant-type cytochrome P450, CYP90C1 (Kim et al., 1998). Sequence analysis suggests that ROT3 is involved in the biosynthesis of steroids (Kim et al., 1998) and the overexpression of ROT3 triggers the specific elongation of leaves in the longitudinal direction (Kim et al., 1999). A homology search revealed a closely related P450, CYP90D1, in the genome of Arabidopsis. The loss-of-function of CYP90D1 does not show any morphological phenotype; however, cyp90d1/ rot3-1 double mutants display a severe dwarf phenotype, like that observed for mutants defective in the biosynthesis of brassinolide (Kim et al., 2005). Biochemical analyses strongly suggest that ROT3 catalyzes the conversion of typhasterol to castasterone, which has been deemed the activation step of BRs (Kim et al., 2005). Considering that mutations in the other genes for the biosynthesis of brassinosteroids severely affect plant shape, the specific defects in leaf length seen in the rot3-1 null mutation is surprising. Moreover, the darkness-induced petiole elongation is lost in the rot3-1 mutant, while the skotomorphogenesis of seedlings is not affected by the rot3-1 null mutation (Kim et al., 2005). Thus, ROT3 may be a leaf-specific factor of brassinosteroid biosynthesis that is involved in photomorphogenesis of leaves. Mechanisms of the photomorphogenesis of leaves, in particular the shade-avoidance syndrome, may be revealed in further studies on the photoregulation of ROT3 and CYP9OD1 gene function.

\section{Interaction between the control of cell number and the control of cell size}

Although leaf morphogenesis is considered the sum of cell growth and cell proliferation, it is not simply the sum of these two events. As previously discussed (Tsukaya, 2002a, b; 2003), decreased cell proliferation in leaves appears to result in an increase in the volume of each cell. This phenomenon is termed «compensation» (Tsukaya, 1998; 2002b, c; 2003; Beemster et al., 2003). For example, defects in the STRUWWELPETER (SWP) gene (Autran etal., 2002) and in the DEFORMEDROOTSANDLEAVES1 (DRL1) gene (Nelissen et al., 2003) result in a narrow, irregular shape of small leaves with a decreased number of parenchymatous cells. SWP is homologous to the Med150/RGR1-like subunits of the Mediator transcriptional regulatory complex (Autran et al., 2002) and DRL1 is a gene for the ATP/GTP binding protein and may be associated with the elongator complex (Nelissen et al., 2003). In these mutants, the decreased number of leaf cells seems to be associated with increased cell volume. Similarly, a loss-offunction mutation of the AINTEGUMENTA (ANT) gene, a member of the AP2/EREBP family, typically results in small leaves with 
fewer cells of larger volume as compared with wild-type cells (Mizukami and Fischer, 2000). In contrast, ANT overexpression in petals causes an increase in cell number without a change in cell size. These observations suggest that, while a decrease in cell number may trigger an increase in cell volume, an increase in cell number does not trigger a decrease in cell volume, as reviewed by Tsukaya (2002a; 2003). Thus, compensation is not a general rule for maintaining a particular leaf size, but, rather, it is thought to be the result of some unknown cell-cell communication.

What are the molecular mechanisms behind this curious phenomenon? Compensation is specifically observed in leaves (and floral organs as modified leaves). This may be closely related to the fact that leaves are the only organs in plants that have a determinate fate. In this sense, understanding the mechanism of compensation is important to understanding how the final size and shape of a determinate organ are determined. A compensation-like phenomenon has also been observed in animal organs and the presence of a «total mass checkpoint» has been hypothesized (Potter and $\mathrm{Xu}, 2001$ ). If compensation is a general rule for multicellular organs of determinate fate in both plants and animals, then the molecular mechanism of this phenomenon needs to be identified in order to understand the fundamental mechanisms of organogenesis in multicellular organisms. The leaf is a good model for pursuing this important theme.

Recently, Nishimura et al. (2004) showed that compensation is not observed in multiple mutants for Arabidopsis histidine kinase ( $A H K$ ) genes, which are defective in cytokinin perception. The $A h k$ multiple mutant develops much smaller leaves with a substantially reduced number of leaf cells as compared with wild type. However, the growth and final size of the leaf cells are normal in these mutants (Nishimura et al., 2004). This fact suggests that cytokinin signaling might be involved in the compensatory system. Further analysis of the molecular mechanism of compensation is needed.

\section{Environmental adaptation and adjustment: photomor- phogenesis of leaves}

In this article, the basic components of leaf organogenesis have been reviewed. Although leaf shape is highly dependent on these basic components, the final leaf shape is further adjusted based on environmental conditions during the last stages of leaf development. The following sections will present a brief overview of the adaptive adjustment of leaf shape to two environmental factors, light conditions and gravity.

In many species, including Arabidopsis, low light intensity promotes the elongation of the leaf petiole and inhibits the expansion of the leaf blade (Fig. 5A). This phenomenon is termed a shade-avoidance syndrome, as mentioned in the Introduction. In contrast, high light intensity inhibits the elongation of the leaf petiole and promotes the expansion of the leaf blade. The shadeavoidance syndrome is under the control of signals in response to the red light perceived by phytochromes (phy A to E) in Arabidopsis (e.g., Devlin et al., 1996; Qin et al., 1997; Devlin et al., 1999; Franklin et al., 2003a; Franklin et al., 2003b). The differences between the sizes of the leaf petioles of plants grown under low light and high light conditions are attributable to the length of each cell in the petiole, while the differences between the sizes of the leaf blades under low light and high light conditions represent the sum of the number and sizes of cells in the leaf lamina (Tsukaya et al.,
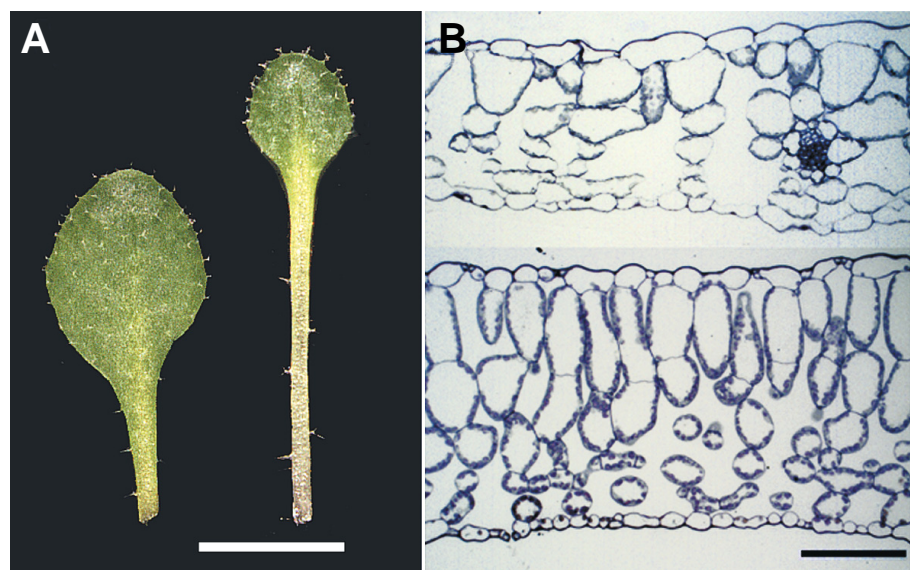

Fig. 5. The light-dependent control of leaf shape and architecture. (A) Under dark conditions (right), leaf blades remain smaller and leaf petioles elongate more than under light conditions (left; i.e., shade-avoidance syndrome). Photo: Courtesy of Mr. T. Kozuka, Graduate University for Advanced Studies, Japan. Bar, $5 \mathrm{~mm}$. (B) High light conditions produce sun leaves (bottom) that differ from the shade leaves (top), which develop under low light conditions, in terms of the shape of the palisade cells and the number of palisade layers. Photo: Courtesy of Dr. S. Yano, Okazaki Institutes for Integrated Bioscience, Japan. Bar, $100 \mu \mathrm{m}$.

2002). The expansion of leaf blades under light is associated with the enhancement of endoreduplication (Kozuka et al., 2005), as reported for etiolated hypocotyls (Gendreau et al., 1998); however, no significant change in the status of endoreduplication has been observed in etiolated leaf petioles (Kozuka et al., 2005). Thus, the differential control of growth between the leaf petioles and leaf blades under various light intensities may be unique for each organ. Interestingly, the effects of a photo-assimilate, sucrose, on growth are positive in both leaf petioles and leaf blades and are altered by light conditions (Kozuka et al., 2005). How the contrasting, differential photomorphogenesis between leaf petioles and leaf blades is exhibited is not yet understood.

In addition to the above-mentioned effects of light in the shadeavoidance syndrome, light conditions also affect the architecture of leaf blades. In many species, light intensity affects the number of layers of palisade cells as well as the shape of the palisade cells. In Arabidopsis under low light conditions (i.e., standard culture conditions for Arabidopsis in a culture room: ca. $60 \mu$ moles $\mathrm{m}^{-2} \mathrm{~s}^{-1}$ in photosynthetically active photon flux density), palisade cells are round and develop into one layer. In contrast, under high light conditions ( $>200 \mu$ moles $\mathrm{m}^{-2} \mathrm{~s}^{-1}$ in photosynthetically active photon flux density), palisade cells develop into two or three layers and are columnar as a result of polarized growth in the leafthickness direction (Fig. 5B). The former type is referred to as a shade leaf and the latter is a sun leaf. Yano and Terashima (2001) reported that in Chenopodium album, the determination of sun or shade leaves in the leaf primordial stage is controlled by longdistance signaling from mature leaves and not by the developing leaf primordia themselves. Interestingly, similar long-distance signaling was also suggested for the adaptive differentiation of stomatal density in leaves at different $\mathrm{CO}_{2}$ concentrations in Arabidopsis (Lake et al., 2001). In Chenopodium album, differences between the architecture of the palisade layers in sun and shade leaves are exhibited by an altered balance between periclinal 
and anticlinal divisions of the palisade cells (Yano and Terashima, 2004). Similar observation was also carried out in Arabidopsis leaves (S. Yano, unpublished data). The signals involved in the control of these cell divisions in the palisade layers is an interesting topic for future studies on the mechanisms of organogenesis in leaves.

\section{Graviresponse of leaves}

While the light condition is the most important environmental factor, the another important environmental factor for plant growth is gravity. The direction of shoot elongation is affected by gravity; however, to date, the responses of plant organs to gravity have been extensively studied only for roots and shoots. Whether leaves react to gravity has yet to be determined, although the behavior of the leaves of wild plants suggests that their graviresponses differ from those of shoots or roots. Arabidopsis is a typical rosette-type plant, with a radial arrangement of foliage that covers the ground on which the plants grow. Do the rosette leaves expand in the direction of gravity, or do they simply bend in the direction opposite the shoot axis?

The graviresponse of leaf expansion in Arabidopsis was investigated by altering the direction of potted seedlings and it was found that the expansion of rosette leaves depended on the direction of the shoots in main. In other words, the rosette leaves of Arabidopsis simply bend in the direction opposite the shoot axis, independent of gravity (Kozuka, T., Mano, E. and Tsukaya, H., unpublished data). However, some climber type species, such as Oxalis spp. and Pueraria lobata, clearly show gravitropism of the leaf petiole (Kozuka, T. and Tsukaya, H., unpublished observations) and even Arabidopsis shows a graviresponse under certain environmental conditions (Mano, E., Kozuka, T. and Tsukaya, H., unpublished data). Further analysis of the gravitropism of leaves is required to understand how leaf expansion is adjusted in natural environments.

\section{Perspective}

Leaf shape is controlled by a fairly complex system, although leaf shape itself is elegantly simple. This is because leaf shape is the most important factor in optimizing plant growth. To better understand plant success, we need to learn more about the mechanisms of leaf morphogenesis. Fortunately, to date, we have accumulated a vast collection of leaf mutants not only for the model plant Arabidopsis (e.g., Berná et al., 1999; Serrano-Cartagena et al., 1999) but also for other plant species. New findings on leaf morphogenesis are accumulating daily. Understanding the mechanisms of leaf organogenesis, plant shape evolution and environmental adaptation depends on the progress made in this research field. The acquired knowledge will be useful also for the bio-design of plant shape and crop productivity. Moreover, if the leaf is considered a model for multicellular organs with determinate fate, understanding leaf organogenesis will provide valuable clues for understanding the general mechanisms of organogenesis in multicellular organisms. The unsolved mechanism of the compensatory system is the key to obtaining these clues.

\section{Acknowledgments}

I wish to thank the members of my laboratory, in particular Dr. G. Horiguchi, for many helpful discussions. This work was supported by a
Grant-in-Aid for Scientific Research on Priority Areas from the Ministry of Education, Science and Culture, Japan; by grants from the Bio-Design Program, Ministry of Agriculture, Forestry and Fisheries of Japan; and by a Grant-in-Aid from the "Ground-based Research Announcement for Space Utilization," Japan Space Forum.

\section{References}

AUTRAN, D., JONAK, C., BELCRAM, K., BEEMSTER, G.T.S., KRONENBERGER, J., GRANDJEAN, O., INZE, D. and TRAAS, J. (2002) Cell numbers and leaf development in Arabidopsis : a functional analysis of the STRUWWELPETER gene EMBO J.21: 6036-6049.

BARTH, C. and CONKLIN, P.L. (2003). The lower cell density of leaf parenchyma in the Arabidopsis thaliana mutant /cd1-1 is associated with increased sensitivity to ozone and virulent Pseudomonas syringae. Plant J. 35: 206-218.

BEEMSTER, G.T.S., FIORANI, F. and INZE, D. (2003). Cell cycle: The key to plant growth control? Trends Plant Sci. 8: 154-158.

BERNA, G., ROBLES, P. and MICOL, J.L. (1999). A mutational analysis of leaf morphogenesis in Arabidopsis thaliana. Genetics 152: 729-742.

BHARATHAN, G., GOLIBER, T.E., MOORE, C., KESSLER, S., PHAM, T. and SINHA, N.R. (2002). Homologies in leaf form inferred from KNOXI gene expression during development. Science 296: 1858-1860.

BOWMAN, J.L. (2004) Class III HD-Zip gene regulation, the golden fleece of ARGONAUTE activity? Bioessays 26: 938-942.

BYRNE, M.E., BARLEY, R., CURTIS, M., ARROYO, J.M., DUNHAM, M., HUDSON, A. and MARTIENSSEN, R.A. (2000). Asymmetric leaves 1 mediates leaf patterning and stem cell function in Arabidopsis. Nature 408: 967-971.

CHINNADURAI, G. (2002) CtBP, an unconventional transcriptional corepressor in development and oncogenesis. Mol. Cell 9: 213-224.

CHUCK, G., LINCOLN, C. and HAKE, S. (1996). KNAT1 induces lobed leaves with ectopic meristems when overexpressed in Arabidopsis. Plant Cel/ 8: 1277-1289.

$\mathrm{CHO}, \mathrm{K} .-\mathrm{H}$. , KIM, G.-T. and TSUKAYA, H. (2005). AN, a CtBP/BARS homolog in plants, differs from CtBP and BARS biochemically. Plant CellPhysiol.46: 250-255.

DE VEYLDER, L., BEECKMAN, T., BEEMSTER, G.T.S., KROLS, L., TERRAS, F. LANDRIEU, I., VAN DER SCHUEREN, L., MAES, S., NAUDTS, M. and INZÉ, D. (2001) Functional analysis of cyclin-dependent kinase inhibitors of Arabidopsis. Plant Cell 13:1653-1667.

DEVLIN, P.F., HALLIDAY, K.J., HARBERD, N.P. and WHITELAM, G.C. (1996). The rosette habit of Arabidopsis thaliana is dependent upon phytochrome action: novel phytochromes control internode elongation and flowering time. Plant J. 10 1127-1134.

DEVLIN, P.F., ROBSON, P.R.H., PATEL, S.R., GOOSEY, L., SHARROCK, R.A. and WHITELAM, G.C. (1999). Phytochrome D acts in the shade-avoidance syndrome in Arabidopsis by controlling elongation growth and flowering time. Plant Physiol 119: $909-915$

DINNENLY, J.R., YADEGARI, R., FISCHER, R.L., YANOFSKY, M.F. and WEIGEL, D. (2004) The role of JAGGED in shaping lateral organs. Development 131:11011110.

DONNELLY, P.M., BONETTA, D., TSUKAYA, H., DENGLER, R. and DENGLER N.G. (1999) Cell cycling and cell enlargement in developing leaves of Arabidopsis. Dev. Biol. 215: 407-419.

EMERY, J.F., FLOYD, S.K., ALVAREZ, J., ESHED1, Y., HAWKER, N.P., IZHAKI, A., BAUM, S.F. and BOWMAN, J.L. (2003). Radial patterning of Arabidopsis shoots by Class III HD-ZIP and KANADI genes. Curr. Biol. 13: 1768-1774.

ESHED, Y., BAUM, S.F., PEREA, J.V. and BOWMAN, J.L. (2001). Establishment of polarity in lateral organs of plants. Curr. Biol. 11: 1251-1260.

FLOYD, S.K. and BOWMAN, J.L. (2004) Gene regulation: Ancient microRNA target sequences in plants. Nature 428: 485-486.

FOLKERS, U., KIRIK, V., SCHOBINGER, U., FALK, S., KRISHNAKUMAR, S. POLLOCK, M.A., OPPENHEIMER, D.G., DAY, I., REDDY, A.S.N., JURGENS, G and HULSKAMP, M. (2002). The cell morphogenesis gene ANGUSTIFOLIA encodes a CtBP/BARS-like protein and is involved in the control of the microtubule cytoskeleton. EMBO J. 21: 1280-1288.

FRANKLIN, K.A., PRAEKELT, U., STODDART, W.M.M., BILLINGHAM, O.E., HALLIDAY, K.J. and WHITELAM, G.C. (2003a). Phytochromes B, D and E act 
redundantly to control multiple physiological responses in Arabidopsis. Plant Physiol. 131: 1340-1346.

FRANKLIN, K.A., DAVIS, S.J., STODDART, W.M., VIERSTRA, R.D. and WHITELAM, G.C. (2003b). Mutant analyses define multiple roles for Phytochrome $C$ in Arabidopsis photomorphogenesis. Plant Cell 15: 1981-1989.

FUKUDA, T., YOKOYAMA, J. and TSUKAYA, H. (2003) The evolutionary origin of indeterminate leaves in Meliaceae: phylogenetic relationships among species in the genera Chisocheton and Guarea, as inferred from sequences of chloroplast DNA. Int. J. Plant Sci. 164: 13-24.

GENDREAU, E., HOFTE, H., GRANDJEAN, O., BROWN, S. and TRAAS, J. (1998) Phytochrome controls the number of endoreduplication cycles in the Arabidopsis thaliana hypocotyl. Plant $J$ 13: 221-230.

HA, C.-H., JUN, J.-H., NAM, H.-G. and FLETCHER, J.C. (2004) BLADE-ONPETIOLE1 encodes a BTB/POZ domain protein required for leaf morphogenesis in Arabidopsis thaliana. Plant Cell Physiol. 45: 1361-1370.

HA, C.-H., KIM, G.-T., KIM, B.-C., JUN, J.-H., SOH, M.-S., UENO, Y., MACHIDA, Y., TSUKAYA, H. and NAM, H.-G. (2003) The BLADE-ON-PETIOLE gene controls leaf pattern formation through regulation of meristematic activity. Development 130: $161-172$.

HAREVEN, D., GUTFINGER, T., PARNIS, A., ESHED, Y. and LIFSCHITZ, E. (1996). The making of a compound leaf: Genetic manipulation of leaf architecture in tomato. Cell 84: 735-744.

HOFER, J., GROULAY, C., MICHAEL, A. and ELLIS, T.H.N. (2001). Expression of a class 1 knotted1-like homeobox gene is down-regulated in pea compound leaf primordial. Plant Mol. Biol. 45: 387-398.

HOFER, J., TURNER, L., HELLENS, R., AMBROSE, M., MATTHEWS, P., MICHAEL, A. and ELLIS, N. (1997). UNIFOLIATA regulates leaf and flower morphogenesis in pea. Curr. Biol. 7: 581-587.

HORIGUCHI, G., KIM, G.-T. and TSUKAYA, H. (2005). The transcription factor AtGRF5 and the transcription coactivator $A N 3$ regulate cell proliferation in leaf primordia of Arabidopsis thaliana. Plant J. 43: 68-78.

IMAICHI, R., NAGUMO, S. and KATO, M. (2000). Ontogenic anatomy of Streptocarpus grandis (Gesneriaceae) with implications for evolution of monophyly. Ann. Bot. 86: 37-46.

IWAKAWA, H., UENO, Y., SEMIARTI, E., ONOUCHI, H., KOJIMA, S., TSUKAYA, H., HASEBE,M., SOMA, T., IKEZAKI, M., MACHIDA, C. and MACHIDA, Y. (2002) The ASYMMETRIC LEAVES2 gene of Arabidopsis thaliana, required for formation of a symmetric flat leaf lamina, encodes a member of a novel family of proteins characterized by cysteine repeats and a leucine zipper. Plant Cell Physiol.43: 467478.

JONG, K. and BURTT, B.L. (1975). The evolution of morphological novelty exemplified in the growth patterns of some Gesneriaceae. New Phytol. 75: 297-311.

KERSTETTER, R.A., BOLLMAN, K., TAYLOR, R.A., BOMBLIES K. and POETHIG, R.S. (2001). KANADI regulates organ polarity in Arabidopsis. Nature 411: 706709.

KIDNER, C.A. and MARTIENSSEN, R.A. (2004). Spatially restricted microRNA directs leaf polarity through ARGONAUTE1. Nature 428: 81-84.

KIM, G.-T., FUJIOKA, S., KOZUKA, T., TAX, F.E., TAKATSUTO, S., YOSHIDA, S. and TSUKAYA, H. (2005) CYP90C1 and CYP90D1 are involved in the different steps in the brassinosteroids biosynthesis pathway in Arabidopsis thaliana. Plant J. 41: 710-721.

KIM, G.-T., SHODA, K., TSUGE, T., CHO, K.-H., UCHIMIYA, H., YOKOYAMA, R., NISHITANI, K. and TSUKAYA, H. (2002) The ANGUSTIFOLIA gene of Arabidopsis, a plant $C t B P$ gene, regulates leaf-cell expansion, the arrangement of cortical microtubules in leaf cells and expression of a gene involved in cell-wall formation. EMBO J. 21: 1267-1279.

KIM, G.-T., TSUKAYA, H., SAITO, Y. and UCHIMIYA, H. (1999) Changes in the shapes of leaves and flowers upon overexpression of the novel cytochrome P450 in Arabidopsis. Proc. Natl. Acad. Sci., USA, 96: 9433-9437.

KIM, G.-T., TSUKAYA, H. and UCHIMIYA, H. (1998) The ROTUNDIFOLIA3 gene of Arabidopsis thaliana encodes a new member of the cytochrome $\mathrm{P} 450$ family that is required for the regulated polar elongation of leaf cells. Genes Dev. 12: 23812391.

KIRIK, V., SIMON, M., HUELSKAMP, M. and SCHIEFELBEIN, J. (2004). The ENHANCER OF TRY AND CPC1 gene acts redundantly with TRIPTYCHON and CAPRICE in trichome and root hair cell patterning in Arabidopsis. Dev. Biol. 268:
506-513.

KOZUKA, T., HORIGUCHI, G., KIM, G.-T., OHGISHI, M. SAKAI, T. and TSUKAYA, H. (2005) The Different Growth Responses of the Arabidopsisthaliana Leaf Blade and the Petiole during Shade Avoidance are regulated by Photoreceptors and Sugar. Plant Cell Physiol.46: 213-223.

LACROIX, C.R. and SATTLER. R. (1994). Expression of shoot features in early leaf development of Murraya paniculata (Rutaceae). Can. J. Bot. 72: 678-687.

LAKE, J.A., QUICK, W.P., BEERLING, D.J. and WOODWARD, F.I. (2001). Signals from mature to new leaves. Nature 411: 154.

LINCOLN, C., LONG, J., YAMAGUCHI, J., SERIKAWA, K. and HAKE, S. (1994).A Knotted1-like homeobox gene in Arabidopsis is expressed in the vegetative meristem and dramatically alters leaf morphology when overexpressed in transgenic plants. Plant Cel/ 6: 1859-1876.

MCCONNELL, J.R. and BARTON, M.K. (1998). Leaf polarity and meristem formation in Arabidopsis. Development 125: 2935-2942.

MCCONNELL, J.R., EMERY, J.F., ESHED, Y., BAO, N., BOWMAN J. and BARTON, M.K. (2001). Role of PHABULOSA and PHAVOLUTA in determining radial patterning in shoots. Nature 411: 709-713.

MIZUKAMI, Y. and FISCHER, R.L. (2000). Plant organ size control: AINTEGUMENTA regulates growth and cell numbers during organogenesis. Proc. Natl. Acad. SCi. USA, 97: 942-947.

NAGATANI, A., CHORY, J. and FURUYA, M. (2001). Phytochrome B is not detectable in the hy3 mutant of Arabidopsis, which is deficient in responding to end-of-day far-red light treatments. Plant Cell Physiol. 32: 1119-1122.

NARDINI, M., SPANO, S., CERICOLA, C., PESCE, A., MASSARO, A., MILLO, E., LUINI, A., CORDA, D. A. and BOLOGNIESI, M. (2003). CtBP/BARS: a dualfunction protein involved in transcription co-repression and Golgi membrane fission. EMBO J. 12: 3122-3130.

NARITA, N. N., MOORE, S., HORIGUCHI, G., KUBO, M., DEMURA, T., FUKUDA, H., GOODRICH J. and TSUKAYA, H. (2004) Over-expression of a novel small peptide ROTUNDIFOLIA4 decreases of cell proliferation and alters leaf shape in Arabidopsis. Plant J. 38: 699-713.

NATH, U., CRAWFORD, B.C. CARPENTER, R. and COEN, E. (2003) Genetic control of surface curvature. Science 299:1404-1047.

NELISSEN, H., CLARKE, J.H., DE BLOCK, M., DE BLOCK, S., VANDERHAEGHEN, R., ZIELINSKI, R.E., DYER, T., LUST, S., INZÉ, D. and VAN LIJSEBETTENS, M. (2002). DRL1, a homolog of the yeast TOT4/KTI12 protein, has a function in meristem activity and organ growth in plants. Plant Cell 15: 639-654.

NISHIMURA, C., OHASHI, Y., SATO, S., KATO, T., TABATA, S. and UEGUCHI, C. (2004) Histidine kinase homologs that act as cytokinin receptors possess overlapping functions in the regulation of shoot and root growth in Arabidopsis. Plant Cell 16: 1365-1377.

OHNO, C.K., REDDY, V., HEISLER, M.G.B. and MEYEROWITZ, E.M. (2004) The Arabidopsis JAGGED gene encodes a zinc finger protein that promotes leaf tissue development. Development 131: 1111-1122.

ORI, N., ESHED, Y., CHUCK, G., BOWMAN, J.L. and HAKE, S. (2000). Mechanisms that control knox gene expression in the Arabidopsis shoot. Development 127: 5523-5532.

OTSUGA, D., DEGUZMAN, B., PRIGGE, M.J., DREWS, G.N. and CLARK, S.E. (2001). REVOLUTA regulates meristem initiation at lateral positions. Plant J. 25: 223-236.

PALATNIK, J.F., ALLEN, E., WU, X., SCHOMMER, C., SCHWAB, R., CARRINGTON, J.C. and WEIGEL, D. (2003) Control of leaf morphogenesis by microRNAs. Nature 425:257-263.

POTTER, C.J. and XU, T. (2001). Mechanisms of size control. Curr. Opin. Genet. Dev. 11: $279-286$

QIN, M., KUHN, R., MORAN, S. and QUAIL, P.H. (1997). Overexpressed phytochrome $\mathrm{C}$ has similar photosensory specificity to phytochrome $\mathrm{B}$ but a distinctive capacity to enhance primary leaf expansion. Plant J. 12: 1163-1172.

PRIGGE, M.J. and WAGNER, D.R. (2001). The Arabidopsis SERRATE gene encodes a zinc-finger protein required for normal shoot development. Plant Cell 13:1263-1279.

REED, J.W., NAGPAL, P., POOLE, D.S., FURUYA, M. and CHORY, J. (1993). Mutations in the gene for the red/far-red light receptor phytochrome $B$ alter cell elongation and physiological responses throughout Arabidopsis development. Plant Cell 5: 147-157. 
REINHART, B.J., WEINSTEIN, E.G., RHOADES, M.W., BARTEL B. and BARTEL, D.P. (2002). MicroRNAs in plants. Genes Dev. 16: 1616-1626.

RHOADES, M.W., REINHART, B.J., LIM, L.P., BURGE, C.B., BARTEL, B. and BARTEL, D.P. (2002). Prediction of plant microRNA targets. Cel/ 110: 513-520.

RUTISHAUSER, R. and SATTLER, R. (1985). Complementarity and heuristic value of contrasting models in structural botany. Bot. Jahrb. Syst. 107: 415-455.

SATTLER, R and RUTISHAUSER, R. (1992). Partial homology of pinnate leaves and shoots: orientation of leaflet inception. Bot. Jahrb. Syst. 114: 61-79.

SAWA, S., WATANABE, K., GOTO, K., KANAYA, E., MORITA, E.H. and OKADA, K. (1999). FILAMENTOUS FLOWER, a meristem and organ identity gene of Arabidopsis, encodes a protein with a zinc finger and HMG-related domains. Genes Dev. 13: 1079-1088.

SEMIARTI, E., UENO, Y., TSUKAYA, H., IWAKAWA, H., MACHIDA, C. and MACHIDA, Y. (2001). The ASYMMETRIC LEAVES2 gene of Arabidopsis thaliana regulates formation of a symmetric lamina, establishment of venation and repression of meristem-related homeobox genes in leaves. Development 128: 1771-1783.

SERRANO-CARTAGENA, J., ROBLES, P., PONCE, M.R. and MICOL, J.L. (1999). Genetic analysis of leaf form mutants from the Arabidopsis Information Service collection. Mol. Gen. Genet. 261: 725-739.

SIEGFRIED, K.R., ESHED, Y., BAUM, S.F., OTSUGA, D., DREWS, G.N. and BOWMAN, J.L. (1999). Members of the YABBY gene family specify abaxial cell fate in Arabidopsis. Development 126: 4117-4128.

TANG, G. REINHART, B.J., BARTEL, D.P. and ZAMORE, P.D. (2003). A biochemical framework for RNA silencing in plants. Genes Dev. 17: 49-63.

TSUGE, T., TSUKAYA, H. and UCHIMIYA, H. (1996) Two independent and polarized processes of cell elongation regulate leaf blade expansion in Arabidopsis thaliana (L.) Heynh. Development 122: 1589-1600.

TSUKAYA, H. (1997). Determination of the unequal fate of cotyledons of a one-leaf plant, Monophyllaea. Development 124: 1275-1280.

TSUKAYA, H. (1998) Relationship between shape of cells and shape of the organ. (in Japanese). In Phytohormones and Cell Shape (in Japanese; $\mathrm{H}$. Imazeki and $\mathrm{H}$. Shibaoka, Eds.) pp. 177-184. Gakkai-shuppann Center, Tokyo, Japan.

TSUKAYA, H. (2002a) Interpretation of mutants in leaf morphology: genetic evidence for a compensatory system in leaf morphogenesis that provides a new link between Cell and Organismal theory. Int. Rev. Cytol. 217: 1-39.

TSUKAYA, H. (2002b) Leaf Development. In The Arabidopsis Book eds. C.R.
Somerville and E.M. Meyerowitz, American Society of Plant Biologists, Rockville, MD, doi/10.1199/tab.0072, http://www.aspb.org/downloads/Arabidopsis/ tsukaya.pdf

TSUKAYA, H. (2002c) The leaf index: heteroblasty, natural variation and the genetic control of polar processes of leaf expansion. Plant Cell Physiol. 43: 372-378.

TSUKAYA, H. (2003) Organ shape and size: a lesson from studies of leaf morphogenesis. Curr. Opin. Plant Biol. 6: 57-62.

TSUKAYA, H. (2005) A new member of the CtBP/BARS family from plants: Angustifolia. In CtBP Family Proteins. (ed. G. Cinnadurai), Landes Bioscience, Georgetown, Texas, USA (in press).

TSUKAYA, H., KOZUKA, T. and KIM, G.-T. (2002) Genetic control of petiole length in Arabidopsis thaliana. Plant Cell Physiol. 43: 1221-1228.

TSUKAYA, H. and UCHIMIYA, H. (1997) Genetic analyses of developmental control of serrated margin of leaf blades in Arabidopsis - Combination of mutational analysis of leaf morphogenesis with characterization of a specific marker gene, which expresses in hydathodes and stipules in Arabidopsis. Mol. Gen. Genet. 256: 231-238.

VAN LIJSEBETTENS, M., VANDERHAEGHEN, R., DEBLOCK, M., BAUW, G., VILLARROEL, R. and VAN MONTAGU, M. (1994). An s18 ribosomal-protein gene copy at the Arabidopsis pfl locus affects plant development by its specific expression in meristems. EMBO J. 13: 3378-3388.

VAN STEENIS, C.G.G.J. (1981) Rheophytes of the World. Sijthoff \& Noordhoff, Alpen aan den Rijn.

VAN DER GRAAFF, E., DEN DULK-RAS, A., HOOYKAAS, P.J.J. and KELLER, B. (2000) Activation tagging of the LEAFY PETIOLE gene affects leaf petiole development in Arabidopsis thaliana. Development 127: 4971-4980.

WAITES, R. and HUDSON, A. (1995). Phantastica: a gene required for dorsoventrality in leaves of Antirrhinum majus. Development 121: 2143-2154.

WEN, J., LEASE, K.A. and WALKER, J.C. (2004) DVL, a novel class of small polypeptides: overexpression alters Arabidopsis development. Plant J. 37: 668677.

YANO, S. and TERASHIMA, I. (2001). Separate localization of light signal perception for sun or shade type chloroplast and palisade tissue differentiation in Chenopodium album. Plant Cell Physiol. 42: 1303-1310.

YANO, S. and TERASHIMA, I. (2004). Developmental process of sun and shade leaves in Chenopodium album. Plant Cell Env. 27: 781-793. 